\title{
IDENTIDADE CULTURAL, MULTICULTURALISMO E EDUCAÇÃO
}

\author{
CULTURAL IDENTITY, MULTICULTURALISM AND EDUCATION
}

IDENTIDAD CULTURAL, MULTICULTURALISMO Y EDUCACIÓN

Jose Carlos Santos Debus ${ }^{1}$

${ }^{1}$ Unidade de Educação de Santa Catarina (UNIESC), Florianópolis/SC- Brasil

RESUMo Análises, concepções e experiências pedagógicas, ancoradas no pensamento multicultural na educação escolar se difundiram pelo mundo ocidental como forma de enfrentamento dos conflitos gerados pela globalização e pela tentativa de combater discriminações e preconceitos, gerando assim várias teorias que propõem outro olhar para a compreensão do mundo multiculturalizado que envolvem o espaço ensino/aprendizagem. Este artigo busca refletir sobre essas teorias que têm mostrado uma nova consciência dentro do pensamento humanista, levando em conta os estudos de Stuart Hall, Homi Bhabha e Peter McLaren, que trazem e indicam novos olhares e novas configurações voltadas ao reconhecimento e à valorização de identidades até então invisíveis ou negadas por meio de estruturas educacionais monoculturais. Esses estudos evidenciam-se nos meios educacionais, refletindo e questionando práticas e discursos curriculares, buscando alternativas para compreender o multiculturalismo na pedagogia e no currículo. Para que essa perspectiva continue existindo dentro do campo educacional, se faz necessário que haja uma ressignificação das estruturas curriculares que dão sustentação ao modelo atual de ensino, que estimule novas reflexões acerca da formação de professores e professoras e garanta a existência das políticas educacionais.

Palavras-chave: Identidades; Multiculturas; EducaÇão; FormaÇão de Professores.

ABSTRACT Analyzes, conceptions and pedagogical experiences, based on multicultural thinking in school education, have spread throughout the Western world as a way of confronting the conflicts generated by globalization and the attempt to combat discrimination and prejudice. Thus, generating several theories that propose another look at the understanding of the multiculturalized world that involves the teaching / learning space. This article seeks to reflect on these theories that have shown a new awareness within humanist thinking, taking into account the studies by Stuart Hall, Homi Bhabha and Peter McLaren, 
that bring and indicate new perspectives and new configurations aimed at the recognition and valorization of identities up to then invisible or denied through monocultural educational structures. These studies are evidenced in educational environments, reflecting and questioning curricular practices and discourses, seeking alternatives to understand multiculturalism in pedagogy and curriculum. In order for this perspective to continue to exist within the educational field, it is necessary to have a new meaning in the curricular structures that support the current model of teaching and encourage new reflections on the training of teachers and guarantee the existence of educational policies.

Keywords: Identities; Multicultures; Education; Teacher training.

Resumen Los análisis, concepciones y experiencias pedagógicas, basadas en el pensamiento multicultural en la educación escolar, se difundieron por el mundo occidental como forma de enfrentamiento de los conflictos generados por la globalización y por el intento de combatir discriminaciones y prejuicios. Generando, así, varias teorías que proponen otra mirada para la comprensión del mundo multiculturalizado que involucra el espacio enseñanza / aprendizaje. Nuestra intención en este artículo es reflejar un poco de esas teorías que han mostrado una nueva conciencia dentro del pensamiento humanista. Nuestra reflexión acompaña los estudios de Stuart Hall, Homi Bhabha y Peter McLaren, que traen e indican nuevas miradas y nuevas configuraciones dirigidas al reconocimiento ya la valorización de identidades hasta entonces invisibles o negadas a través de estructuras educativas monocultura. Estos estudios se evidencian en los medios educativos, reflejando y cuestionando prácticas y discursos curriculares buscando alternativas para comprender el multiculturalismo en la pedagogía y en el currículo. Para que esa perspectiva siga existiendo dentro del campo educativo se hace necesario que haya una resignificación de las estructuras curriculares que dan sustentación al modelo actual de enseñanza y estimule nuevas reflexiones sobre la formación de profesores y profesoras y garantice la existencia de las políticas educativas que hasta aquí conquistamos.

Palabras Clave: Identidades; Múltiples culturas; La educación; Formación.

\section{INTRODUÇ̃̃̃o}

O pensamento democrático no Brasil, essencialmente a partir da Constituição de 1988, começou a apontar a necessidade de criar pedagogias que pudessem substituir a cultura do silêncio na escola, imposta por mais de vinte anos de governos ditatoriais. Desse modo, várias teorias envolvendo conceitos de educação democrática intensificaram suas perspectivas nos debates durante os anos 1990 e entramos no século XXI com as ideias libertadoras de Paulo Freire ocupando grande parte do debate democrático, que nos ajudou a entender e defender o princípio da igualdade e da oportunidade como algo vinculado ao direito de acesso à educação escolar e, também, aos projetos de políticas para a educação. Muitas dessas teorias influenciaram diretamente as políticas públicas que modificaram as diretrizes que construíram as novas leis da educação brasileira. Vivemos tempos de desmonte dessas políticas públicas, que afirmaram e reafirmaram o fim de preconceitos e discriminações contra negros, mulheres, índios e outras minorias do Brasil. 
Análises, concepções e experiências pedagógicas, ancoradas no pensamento multicultural na educação escolar se difundiram, em meados do século XX, pelo mundo ocidental como forma de enfrentamento dos conflitos gerados pela globalização do capital e na tentativa de combater discriminações e preconceitos que dificultam aos indivíduos e grupos acolherem e conviverem com a pluralidade e as diferenças culturais, gerando assim várias teorias que, propondo outro olhar para a compreensão do mundo multiculturalizado, nos permitem entender a relação entre escola e sujeitos dentro de um universo conflitivo, que envolve o espaço ensino/aprendizagem.

Nossa intenção neste artigo é fazer uma reflexão acerca das teorias multiculturais desenvolvidas pelos estudos de Stuart Hall (2003, 2006), Homi Bhabha (2005) e Peter McLaren (2000), que trazem e indicam novos olhares e novas configurações voltadas ao reconhecimento e à valorização de identidades até então invisíveis ou negadas por estruturas educacionais monoculturais. Trabalhamos com alguns recortes desses estudos que, em nosso entendimento, evidenciam-se nos meios educacionais refletindo e questionando práticas e discursos curriculares a partir de uma linguagem que possibilite a educadores e trabalhadores culturais criticar e transformar as práticas sociais e culturais.

Inicialmente, apresentamos o conceito de multiculturalismo desenvolvido por Stuart Hall $(2003,2006)$. Hall trabalha com o conceito como uma teoria inacabada de uma complexidade que, muitas vezes, a torna incompreensível. Esse sociólogo chama a atenção para pensarmos o homem da pós-modernidade como um sujeito fragmentado por diversas identidades culturais. Ao contrário do homem moderno, que viveu centrado num ciclo onde permanecia o mesmo por toda a vida. Entender como esse descentramento se constrói e se movimenta é nossa intenção neste momento.

Da mesma forma que há um descentramento do homem contemporâneo, também há um descentramento do conceito de cultura. E para entender os deslocamentos desse conceito, apresentamos num segundo momento a perspectiva de Homi Bhabha (2005), que problematiza multiculturalismo a partir de novos significados de cultura e chama a atenção para o conceito de diferença cultural, onde o hibridismo prevalece e ameaça a autoridade cultural.

No terceiro momento, apresentamos algumas reflexões de Peter McLaren (2000), numa tentativa de entender como as teorias desenvolvidas por Hall e Bhabha se processam dentro de um contexto político e pedagógico. McLaren trabalha com a problemática do multiculturalismo a partir dos interesses sociais, políticos e econômicos estabelecidos dentro das relações de poder. Para esse estudioso, há uma nova relação entre identidade e diferença, que é marcada por um multiculturalismo crítico e de resistência.

\section{Multiculturalismo e IDENTIDADE}

Nas páginas seguintes veremos que o termo multiculturalismo pode ser definido a partir de diversos enfoques, que variam de acordo com o contexto histórico, social e econômico. Em sua linha geral, podemos dizer que o multiculturalismo pode ser entendido como um movimento de ideias que buscam um tipo de consciência coletiva para a pluralidade das experiências culturais (HALL, 2006). Essa pluralidade (diversidade) cultural é sempre 
o centro das preocupações das propostas multiculturalistas que projetam novas estratégias políticas, no sentido de tornar visíveis os grupos marginalizados social e culturalmente. Stuart Hall (2003) observa que o multiculturalismo é um termo que se expandiu e se modifica em todo o mundo. Para esse autor, o vocábulo multiculturalismo é hoje utilizado universalmente. No entanto,

\footnotetext{
[...] sua proliferação não contribuiu para estabilizar ou esclarecer seu significado. Assim como outros termos relacionados - por exemplo, 'raça', etnicidade, identidade, diáspora - o multiculturalismo se encontra tão discursivamente enredado que só pode ser utilizado 'sob rasura'. Contudo, na falta de conceitos menos complexos que nos possibilitem refletir sobre o problema, não resta alternativa senão continuar utilizando e interrogando esse termo (HALL, 2003, p. 49).
}

Para além disso, Hall (2003) afirma que assim como existem diferentes sociedades multiculturais, também há multiculturalismos diversos. Nesse sentido, esse autor divide o multiculturalismo em: multiculturalismo conservador, aquele que prega a assimilação das diferenças pelas tradições e costumes da maioria; multiculturalismo liberal, ancorado em uma cidadania individual e universal, tolera algumas práticas culturais apenas no domínio privado; multiculturalismo pluralista, apoia as diferenças dos grupos dentro de uma ordem político-comunitária; multiculturalismo comercial, acredita que os problemas de diferença cultural serão resolvidos no consumo privado, sem necessidade de redistribuir o poder e os recursos; multiculturalismo corporativo, administra as diferenças culturais da minoria, visando os interesses do centro; multiculturalismo crítico, enfoca o poder, o privilégio e a hierarquia das opressões e projeta os movimentos de resistência.

Nos últimos anos, tem-se falado muito em "crise de identidade do sujeito" (HALL, 2006, p. 8). Uma crise que vem fazendo que o sujeito, sempre entendido como unificado, se apresente deslocado por conta das mudanças econômicas e sociais ocorridas em escala global. Essas mudanças fragmentam as diversas identidades culturais de classe, gênero, sexualidade, etnia e nacionalidade que, antes, eram sólidas localizações, onde o sujeito moderno se encaixava socialmente, hoje se encontra com as fronteiras menos definidas, provocando no sujeito pós-moderno uma crise de identidade. Em seu livro $A$ identidade cultural na pós-modernidade, Stuart Hall (2006) ilustra esse sujeito fragmentado e suas identidades culturais e faz uma viagem pelas sociedades, desde o iluminismo até os dias atuais, aprofundando as questões de identidades que envolvem o sujeito. Segundo ele, há três concepções muito diferentes de identidade do sujeito que necessitam ser distinguidas em nossas sociedades: o sujeito do iluminismo, o sociológico e o pós-moderno.

O sujeito do iluminismo apresenta-se como um indivíduo totalmente centrado, dotado da capacidade de raciocinar, cujo centro consiste num núcleo interior, que aparecia quando o sujeito nascia e permanecia basicamente o mesmo ao longo da vida. O sujeito sociológico reflete a complexidade do mundo moderno e a consciência de que esse núcleo interior do indivíduo não é autônomo, e sim construído nas relações sociais onde as identidades são formadas. Por último, o sujeito pós-moderno, o qual é formado por várias identidades muitas vezes contraditórias ou não resolvidas. Aqui, conforme observa o autor, “[...] a identidade é definida historicamente e não biologicamente. $\mathrm{O}$ sujeito assume identidades 
diferentes em diferentes momentos, identidades que não são unificadas ao redor do 'eu' coerente" (HALL, 2006, p. 10-12).

Sendo assim, o processo de identificação tornou-se mais provisório, variável e problemático em contextos que ocorrem uma concepção de identidade mutável, transitória, contraditória e resultante das relações sociais entre os sujeitos. Dessa forma,

[...] as velhas identidades, que por tanto tempo estabilizaram o mundo social, estão em declínio, fazendo surgir novas identidades e fragmentando o indivíduo moderno, até aqui visto como um sujeito unificado. Assim a chamada 'crise de identidade' é vista como parte de um processo mais amplo de mudança, que está deslocando as estruturas e processos centrais das sociedades modernas e abalando os quadros de referência que davam aos indivíduos uma ancoragem estável no mundo social (HALL, 2006, p. 11).

Uma mudança estrutural está fragmentando as diversas identidades culturais de classe, gênero, sexualidade, etnia e de nacionalidade, e determinando fronteiras menos definidas, provocando uma crise de identidade onde as representações culturais do sujeito pós-moderno e fragmentado, formado por identidades temporárias, que pode ser identificado e se identificar com várias posições diferentes e contraditórias, podem ser denominadas de "jogo de identidades" (HALL, 2005, p. 18). O autor cita como exemplo o caso do presidente Bush que, em 1991, indicou um juiz negro de posição política conservadora à Suprema Corte dos EUA. Assim, o presidente, "jogando o jogo das identidades", conquistava o apoio tanto dos negros quanto dos brancos. Destaca Hall:

No julgamento de Bush, os eleitores brancos (que podiam ter preconceitos em relação a um juiz negro) provavelmente apoiaram o juiz porque ele era conservador em termos da legislação de igualdade de direitos, e os eleitores negros (que apoiam políticas liberais em questões de raça) apoiaram o juiz porque ele era negro. Em síntese, o presidente estava 'jogando o jogo das identidades' (HALL, 2006, p. 19).

Outro aspecto fundamental dessa questão da identidade está relacionado às características de mudança na modernidade tardia onde as sociedades modernas não contam com um centro articulador e organizador. Sendo assim, o conceito de identidade passa a ter caráter diferenciado em relação à forma iluminista e sociológica. Hall cita Marx, Freud, Lacan, Saussure e Foucault como grandes desarticuladores desse sujeito que, com suas ideias, colocam as variadas possibilidades de identidades.

Para Hall (2006), um dos grandes "descentramentos" do pensamento ocidental do século XX vem da descoberta do inconsciente, onde ele afirma que:

[...] a teoria de Freud de que nossas identidades, nossa sexualidade e a estrutura de nossos desejos são formadas com base em processos psíquicos e simbólicos do inconsciente, que funciona de acordo com uma lógica muito diferente daquela da Razão, arrasa com o conceito do sujeito cognoscente e racional provido de uma identidade fixa e unificada - 'o penso, logo existo', do sujeito de Descartes (HALL, 2006, p. 36). 
A leitura que os pensadores da psicanálise fazem é que a imagem do eu como inteiro e unificado é algo que a criança aprende gradualmente, em partes e com grandes dificuldades (HALL, 2006). Essa imagem é formada na relação com os outros. Conforme Hall (2006, p. 36), “a formação do eu no 'olhar' do Outro, de acordo com Lacan, inicia a relação da criança com os sistemas simbólicos forma dela mesma e é, assim, o momento da sua entrada nos vários sistemas de representação simbólica - incluindo a língua, a cultura e a diferença sexual". Sobre a linguagem, a qual é apresentada como um sistema social e não como um sistema individual, o comparativo aqui é o linguista Ferdinand Saussure, que é apontado como responsável por esse descentramento: "Saussure argumentava que nós não somos, em nenhum sentido, os autores das afirmações que fazemos ou dos significados que expressamos na língua" (HALL, 2006, p. 40). Os significados das palavras não são fixos. Eles dependem das relações de similaridades e diferenças que as palavras têm com as outras palavras no interior de uma língua. Como observa Hall (2006, p. 41),

[...] o que os modernos filósofos da linguagem - como Jacques Derrida, influenciado por Saussure -- argumentam é que, apesar de seus melhores esforços, o/a falante individual não pode, nunca, fixar o significado de uma forma final, incluindo o significado de sua identidade. As palavras são ‘multimoduladas'. Elas sempre carregam ecos de outros significados que elas colocam em movimento, apesar de nossos melhores esforços para cerrar o significado.

O descentramento também ocorre no trabalho do filósofo e historiador francês Michel Foucault (apud HALL, 2006), que produziu uma espécie de "genealogia do sujeito moderno". Para o sociólogo jamaicano,

Foucault destaca outro tipo de poder, que ele chama de 'poder disciplinar' [...]. O poder disciplinar está preocupado, em primeiro lugar, com a regulação, a vigilância é o governo da espécie humana ou de populações inteiras e, em segundo lugar, do indivíduo e do corpo. Seus locais são aquelas novas instituições que se desenvolveram ao longo do século XIX e que 'policiam' a disciplinam as populações modernas - oficinas, quartéis, escolas, prisões, hospitais, clínicas e assim por diante (HALL, 2006, p. 42).

Aqui, o caráter abrangente dos regimes disciplinares do moderno poder administrativo coloca o paradoxo de que, quanto mais coletiva e organizada a natureza das instituições da modernidade tardia, tanto maior o isolamento, a vigilância e a individualização do sujeito (HALL, 2006).

Hall (2006) destaca também o impacto causado pelo feminismo não só no campo teórico, mas, principalmente, como movimento social que se caracterizou como um dos principais descentramentos dos conceitos do sujeito iluminista e sociológico. Para esse estudioso, o feminismo é um dos novos movimentos sociais que politizaram a identidade feminina e contribuíram, de forma importante, para a contestação do status quo. Os movimentos feministas se opunham tanto à política liberal capitalista do Ocidente quanto à política estalinista do Oriente. Assim, o "feminismo abriu para contestação política, arenas inteiramente novas de vida social: a família, a sexualidade, o trabalho doméstico, a divisão doméstica do trabalho, o cuidado com as crianças, etc.” (HALL, 2006, p. 45). 
No entanto, questiona-se ainda como esse sujeito descentrado e fragmentado é colocado em termos de representação de suas identidades culturais em um espaço onde as culturas nacionais em que nascemos ainda compõem uma das principais fontes de identidade cultural e toda essa fragmentação do sujeito e de sua identidade cultural afetou diretamente a identidade nacional construída e consolidada durante a modernidade (HALL, 2006).

De acordo com o autor, a nação pode ser entendida como um sistema de representação cultural que extrapola a noção de legitimidade do ser social, pois as pessoas não são apenas cidadãs, já que partilham uma gama de significados: narrativas, estratégias discursivas, mitos, instituições (HALL, 2006, p. 51). Assim, os diferentes membros das culturas nacionais, independendo de sua cor, classe e gênero, seriam unificados numa única identidade cultural, a identidade do "civilizador". Hall (2006) aponta para o fato de grande parte das nações serem construídas por um processo violento de conquista de diferentes povos, de diversas classes sociais, assim como de várias etnias e gêneros. Nesse sentido, uma cultura nacional é um discurso, um modo de construir sentidos que influenciam e organizam nossas ações e nosso modo de nos ver. Hall (2006, p. 51) cita o argumento de Benedict Anderson, de que a identidade nacional é uma "comunidade imaginada". Questiona-se assim que estratégias de representação são acionadas para construir essa comunidade? Quais são as representações que dominam as identificações e definem a identidade de um povo? Hall (2006) responde a partir da seleção de cinco elementos principais.

O primeiro deles é a narrativa de nação, como é contada e recontada nas histórias e nas literaturas nacionais, na mídia e na cultura popular onde:

[...] essas fornecem uma série de estórias, imagens, panoramas, cenários, eventos históricos, símbolos e rituais nacionais que simbolizam ou representam experiências partilhadas, as perdas, os triunfos e os desastres que dão sentido à nação. Como membros de tal 'comunidade imaginada', nos vemos, no olho de nossa mente, como compartilhando dessa narrativa. Ela dá significado e importância à nossa monótona existência, conectando nossas vidas cotidianas com um destino nacional que preexiste a nós e continua existindo após nossa morte (HALL, 2006, p. 52).

O segundo elemento selecionado dá ênfase às origens, na continuidade, na tradição e na intemporalidade. "Os elementos do caráter nacional permanecem imutáveis, apesar de todas as vicissitudes da História. Está lá desde o nascimento, unificado e contínuo, imutável ao longo de todas as mudanças, eterno" (HALL, 2006, p. 53).

O terceiro elemento apontado por Hall (2006) é a invenção da tradição. "Tradição inventada significa um conjunto de práticas, de natureza real ou simbólica, que buscam inculcar certos valores e normas de comportamentos através da repetição, a qual, automaticamente, implica continuidade com um passado histórico adequado" (HALL, 2006, p. 54).

$\mathrm{O}$ quarto elemento da narrativa da cultura nacional é o mito fundacional, que Hall (2006, p. 55) explica como aquele que localiza:

[...] a origem da nação, do povo e de seu caráter nacional num passado tão distante que eles se perdem nas brumas do tempo, não do tempo 'real', mas do tempo 'mítico'. Tradições inventadas tornam as confusões e os desastres da história inteligíveis, transformando a desordem em 'comunidade' e desastres em triunfos. 
Por fim, como quinto elemento, esse sociólogo afirma que a identidade nacional é também ancorada na ideia de um povo puro, original. Sendo assim, a cultura nacional atua como fonte de significados culturais dentro de um foco de identificação em sistema de representação, onde as sutilezas desse processo mostram suas ambiguidades e contradições, pois uma cultura nacional vive entre o passado e o futuro, num dado momento se dirigindo ao passado e suas glórias, e em outro momento tentando seguir em direção ao futuro (HALL, 2006, p. 56).

Outras categorias também são utilizadas muitas vezes como referencial para unificar e representar um único povo, como as categorias de raça e etnia, embora, como afirma o autor, essas categorias sejam apenas tentativas de unificar identidades nacionais, pois as nações são culturas híbridas e essas categorias são categorias discursivas e não biológicas (HALL, 2006). Torna-se, assim, muito mais difícil unificar a identidade nacional em torno da raça. Para Hall (2006, p. 63),

[...] a raça não é uma categoria biológica ou genética que tenha qualquer validade científica. Há diferentes tipos e variedades, mas elas estão tão largamente dispersas no interior do que chamamos de 'raças' quanto entre uma 'raça' e outra. A diferença genética - o último refúgio das ideologias racistas - não pode ser usada para distinguir um povo de outro.

Dessa forma, ao discutir se as identidades nacionais estão sendo deslocadas, o autor procura ver a forma pela qual as culturas nacionais buscam colocar as diferenças em uma única identidade, pois essas não estão livres do jogo do poder, das contradições e divisões internas, de lealdades e diferenças sobrepostas. Conforme afirma Hall (2006, p. 65), "quando vamos discutir se as identidades nacionais estão sendo deslocadas, devemos ter em mente a forma pela qual as culturas nacionais contribuem para 'costurar' as diferenças numa única identidade".

No próximo subtítulo, nosso estudo segue o pensamento de Homi Bhabha a partir de alguns recortes do seu livro $O$ local da cultura (2005), onde o autor preconiza o deslocamento do debate da diversidade cultural para diferença cultural, possibilitando outro olhar para o fazer cultura.

\section{OUTROS SIGNIFICADOS DE IDENTIDADE E CULTURA}

No mundo contemporâneo, as questões que envolvem o termo cultura têm diferentes abordagens e são constantemente redimensionadas em várias esferas. As tentativas de compreender essas abordagens, que envolvem a cultura e sua produção, permitem diálogos com perspectivas que também problematizam o multiculturalismo, como é o caso da teoria desenvolvida por Homi Bhabha, onde ele propõe pensar o limite da cultura como um problema de enunciação e atenta para a abertura da "possibilidade de outros tempos de significado cultural e outros espaços narrativos" (BHABHA, 2005, p. 45). A partir da análise da teorização, Bhabha defende o lugar híbrido da cultura na compreensão desta como enunciação, como algo que busca reforçar a reivindicação política, e procura operar com os 
conceitos de tradução, negociação, lugar e diferença. O autor articula um modo de pensar a nação como uma pluralidade e coloca o lugar de enunciação como rejeição às categorias puras e elege o híbrido como fio condutor.

Assim, o conceito de diferença cultural concentra-se no problema da ambivalência da autoridade cultural e na tentativa de dominar em nome da supremacia cultural, e possibilita que o hibridismo se torne uma ameaça à autoridade cultural, subvertendo o conceito de lugar e identidade pura da autoridade dominante por meio da ambivalência criada pela negação, variação, repetição e deslocamento. Desse modo, esses traços do hibridismo fazem que este transgrida todo o projeto do discurso dominante e exija o reconhecimento da diferença, questionando e deslocando o valor simbólico do discurso. Assim, Bhabha (2005) propõe o deslocamento da discussão da diversidade para a diferença cultural. Para esse pensador, a diversidade cultural é o reconhecimento de conteúdos e costumes culturais pré-dados que originam as noções liberais de multiculturalismo, de intercâmbio cultural ou da cultura da humanidade.

Essa perspectiva da enunciação nos permite ver que cada pessoa traz uma herança cultural significativa, experiências e práticas, valores, características e formação específica para o exercício de suas funções e para o viver de sua própria existência, e isso determina a comunicação que trava no seu cotidiano em todos os níveis e dimensões. E é em meio a esse cotidiano que a nação constrói a sua narrativa. "Das margens da modernidade, nos extremos insuperáveis do contar histórias, encontramos a questão da diferença cultural como a perplexidade de viver, e escrever, a nação" (BHABHA, 2005, p. 227).

Toda essa concepção do hibridismo desenvolve-se no sentido de entender as fronteiras da cultura como uma problemática relativa à manifestação da diferença cultural. Isso implica ir além do reconhecimento e do acolhimento das diversidades, da crítica ao racismo, às discriminações e às exclusões. Para Bhabha (2005), o conceito de diversidade nos leva somente a uma discussão filosófica, enquanto a ideia de diferença cultural nos conduz à enunciação da cultura, onde estão as diferenças e discriminações que formam a base da trama de relações de poder e de práticas sociais. Essa ideia permite o olhar para novas formas de lidar com a cultura como produção irregular, incompleta de sentido e de valor.

Sendo assim, a questão da identidade nunca é a afirmação de uma postura pré-dada, nunca é uma profecia autocumpridora - é sempre a produção de uma imagem de identidade e a transformação do sujeito ao assumir aquela imagem. A demanda da identificação implica a representação do sujeito na ordem diferenciadora da alteridade. A identificação é sempre o retorno de uma imagem de identidade que traz a marca da fissura no lugar do Outro (BHABHA, 2005). Conforme o autor, essa imagem é sempre um acessório da autoridade e da identidade; a imagem não deve ser nunca lida mimeticamente como a aparência de uma realidade. Para Bhabha (2005), o acesso à imagem da identidade só é possível na negação de qualquer ideia de originalidade ou plenitude. Desse modo, a imagem, a um só tempo, é uma substituição metafórica, uma ilusão de presença e uma metonímia, um signo de sua ausência e perda.

Homi Bhabha (2005) afirma que o discurso colonial está preso a sua narrativa ideológica como signo da diferença cultural, histórica e racial. Esse discurso é um modo de representação paradoxal: "conota rigidez e ordem imutável, como também desordem, de- 
generação e repetição demoníaca" (BHABHA, 2005, p. 105). É esse processo de ambivalência que dá ao estereótipo colonial a sua validade. E essa ambivalência funciona como estratégia discursiva mais significativa do poder tanto na periferia como na metrópole. Por isso, é importante reconhecer o estereótipo como uma forma ambivalente de poder e conhecimento e questionar seu significado, que estabelece posições dogmáticas e moralistas que oprimem e discriminam. Conforme observa esse autor,

[...] o objetivo do discurso colonial é apresentar o colonizado como uma população de tipos degenerados com base na origem racial de modo a justificar a conquista e estabelecer sistemas de administração e instrução [...] o discurso colonial produz o colonizado como uma realidade social que é ao mesmo tempo um 'outro' e ainda assim inteiramente apreensível e visível. [...] ele emprega um sistema de representação, um regime de verdade, que é estruturalmente similar ao realismo (BHABHA, 2005, p. 110).

Assim população colonizada é tomada como causa e efeito do sistema e depende do círculo de interpretação e da demanda do discurso colonial. A cadeia de significação estereotipada é misturada, dividida, perversa e se apresenta de várias formas. Podemos entender isso quando ele diz que,

[...] O negro é ao mesmo tempo selvagem (canibal) e ainda o mais obediente e digno dos servos (o que serve a comida); ele é a encarnação da sexualidade desenfreada e, todavia, inocente como uma criança; ele é o místico, primitivo, simplório e, todavia, o mais escolado e acabado dos mentirosos e manipulador de forças sociais. Em cada caso o que está sendo dramatizado é uma separação - entre raças, culturas, histórias, no interior de histórias [...] (BHABHA 2005, p. 126).

Esses exemplos de crença contraditória, justos e injustos, moderados e ávidos, vigorosos e escolados, estão colocados no conjunto simbólico do discurso colonial e levantam questões sobre o espaço simbólico da autoridade colonial. Essas questões devem mostrar que o sujeito do discurso colonial, "no momento de projetar-se e se dividir, duplicar, de tornar-se o seu contrário, é um sujeito de tal ambivalência afetiva e perturbação discursiva que a narrativa da história só pode dar como provada a questão colonial" (BHABHA, 2005, p. 144).

No próximo subtítulo, nosso estudo acompanha a ideia de um multiculturalismo crítico e de resistência desenvolvida por Peter McLaren (2000). Nessa ideia, o multiculturalismo crítico vê a cultura como algo conflitivo, não consensual. McLaren (2005) também estabelece diferenciações fundamentais para compreender diversidade e diferença.

\section{Multiculturas E IDENTIDADES Na EDUCAÇÃo}

Peter McLaren (2000) é um estudioso da educação que percebe a existência e as várias maneiras de responder à diversidade étnica, de classe, de gênero, linguística, cultural, de preferência sexual, de idade, de deficiências. E essas respostas, na sua opinião, sofrem a influência de interesses sociais, políticos e econômicos e se encontram dentro das relações de 
poder, configuradas nas formas pelas quais os indivíduos, as organizações, os grupos e as instituições reagem à realidade multicultural. Desse modo, McLaren (2000) traz para contexto da sala de aula o debate envolvendo o multiculturalismo numa perspectiva política e pedagógica que compreende um conjunto de posições diversas, identificadas e descritas por McLaren (2000) como multiculturalismo conservador ou monoculturalismo, multiculturalismo humanista liberal, multiculturalismo liberal de esquerda e multiculturalismo crítico e de resistência ou multiculturalismo revolucionário.

Para McLaren (2000), o multiculturalismo conservador ou monoculturalista adota princípios do darwinismo social, privilegiando a assimilação cultural como mecanismo de integração. $\mathrm{O}$ autor acredita na inferioridade cultural dos diversos grupos étnicos quando comparados aos brancos, por isso defende a assimilação de práticas culturais diferentes, pelas dominantes da cultura branca. McLaren (2000) identifica no multiculturalismo conservador uma postura neocolonial, formada na representação escravista e serviçal ou selvagem, conferida à população negra, como também, na exaltação dos atributos europeus e norte-americanos amparando-se no darwinismo que justifica a supremacia da cultura branca e coloca os não brancos como incivilizados.

Outra forma de ver o multiculturalismo é a humanista liberal, que defende a igualdade entre os seres humanos a partir de diferentes histórias e condições. Conforme McLaren (2000), na visão humanista liberal predomina o imaginário de uma raça comum, pelo qual as diferenças étnicas, de classe e de gênero são menosprezadas. O multiculturalismo humanista liberal concebe uma igualdade natural no interior dos grupos culturais, ancorada na igualdade intelectual de todos os seres humanos. McLaren (2000, p. 119) afirma que essa igualdade, no entanto, está ausente nos Estados Unidos, "não por causa da privação cultural das pessoas latinas e negras, mas porque as oportunidades sociais e educacionais não existem para permitir a todos competir igualmente no mercado capitalista".

Observando o princípio da meritocracia na sociedade ocidental, McLaren (2000) denuncia a camuflagem elaborada pelo discurso do multiculturalismo humanista liberal ao afirmar que o indivíduo conquista seu espaço de acordo com o seu próprio mérito e que as posições alcançadas na sociedade dependem da educação e da competência de cada um. $\mathrm{O}$ olhar liberal acredita que as diferenças sociais sejam atribuídas à ausência de oportunidades sociais e educacionais e não por causa da privação cultural estabelecida por aqueles que, historicamente, controlam o poder. Para esse estudioso, essa visão "resulta frequentemente em um humanismo etnocêntrico e opressivamente universalista, no qual as normas legitimadoras que governam a substância da cidadania são identificadas mais fortemente com as comunidades político-culturais anglo-americanas" (MCLAREN, 2000, p. 120).

Outra forma de multiculturalismo, segundo McLaren (2000), é o liberal de esquerda, o qual trata a diferença como uma essência que existe independentemente de história, cultura ou poder. O multiculturalismo liberal de esquerda enfatiza a diferença cultural e afirma que essa diferença é, normalmente, associada a um passado histórico das verdades culturais, nas quais se desenvolveram os princípios de determinada identidade, os quais superam as forças históricas do contexto social, político e econômico.

McLaren (2000, p. 121) explica que o multiculturalismo liberal de esquerda, normalmente, situa "o significado através da ideia de experiência 'autêntica' na falsa crença de 
que a política de localização de uma pessoa garante uma postura 'politicamente correta"'. O político aqui é reduzido apenas ao individual e as análises são sempre em favor da identidade pessoal e cultural particular. E ele observa, ainda, que:

[...] o significado passa por um processo de produção e precisa ser interrogado para que se possa entender como a identidade está sendo produzida constantemente, através de um jogo de diferença relacionado e refletido por relações, formações e articulações ideológicas e discursivas que se deslocam e se conflitam (MCLAREN, 2000, p. 121).

No entanto, para melhor situar o significado, a ideia de experiência necessita ser entendida como o lugar de produção ideológica e de mobilização. Assim, a experiência "pode ser examinada através da imbricação em nosso conhecimento local e universal e nos modos de inteligibilidade e suas relações com a língua, com o desejo e com o corpo" (MCLAREN, 2000, p. 122). Esse autor chama a atenção para a ideia que resulte em nos aprontar para examinar nossas próprias experiências e vozes no campo da complexidade discursiva e ideológica

O multiculturalismo crítico e de resistência, o fio condutor da obra de Peter McLaren, tem em sua base a teoria social pós-moderna crítica e o pós-estruturalismo de resistência. Como ele mesmo afirma, a sua ideia é desenvolvida "a partir da perspectiva de uma abordagem de significado pós-estruturalista de resistência, e enfatizando o papel que a língua e a representação desempenham na construção de significado e identidade" (MCLAREN, 2000, p. 122).

O pós-estruturalismo, no qual está embasada sua teoria, situa-se em um contexto mais amplo da teoria pós-moderna, qual seja:

\footnotetext{
...aquele arquipélago de disciplinas que está disperso no oceano da teoria social que afirma que signos e significações são essencialmente instáveis e em deslocamento, podendo apenas ser temporariamente fixados, dependendo de como estão articulados dentro das lutas discursivas e históricas particulares (MCLAREN, 2000, p. 123).
}

$\mathrm{Na}$ teoria pós-modernista, as identidades de classe, gênero e etnia explicam o resultado de várias lutas sociais ampliadas sobre signos e representações. Já, na teoria pós-estruturalista, a língua e as representações desempenham um papel fundamental na formação de significados e identidades. Conforme McLaren (2000), o multiculturalismo crítico compreende a representação de etnia, classe e gênero como o resultado de lutas sociais mais amplas sobre signos e significações. Nessa perspectiva, os indivíduos produzem, renovam e reproduzem os significados em um contexto constantemente configurado e reconfigurado pelo poder.

O multiculturalismo crítico e de resistência se recusa a ver a cultura como não conflitiva, harmoniosa e consensual. Para McLaren (2000, p. 123), a democracia deve ser compreendida como tensa e não "como um estado de relações culturais e políticas sempre harmonioso, suave e sem cicatrizes". Dessa forma, o multiculturalismo de resistência não coloca a diversidade como uma meta, mas propõe que a diversidade deve ser afirmada den- 
tro de uma política de crítica e compromisso com a justiça social. McLaren (2000) afirma que a diferença é sempre um produto da história, da cultura, do poder e da ideologia.

Assim, o estudioso canadense propõe que o multiculturalismo crítico aponte aos trabalhadores da educação e da cultura a questão da "diferença", de maneira que não repitam o "essencialismo monocultural dos 'centrismos' (anglocentrismo, eurocentrismo, afrocentrismo, falocentrismo, androcentrismo)" (MCLAREN, 2000, p. 132). Para o autor, as educadoras e educadores, ou as trabalhadoras e trabalhadores culturais:

[...] precisam construir uma política de consolidação de alianças, de sonharem juntos, de solidariedade que vai além da postura condescendente de, por exemplo, 'semana da consciência das raças' que na realidade servem para manter formas de racismo institucionalizado intactas. Nós devemos lutar por uma solidariedade que não está centrada em torno de imperativos de mercado, mas sim que se desenvolve a partir de imperativos de liberdade, libertação, democracia e cidadania crítica (MCLAREN, 2000, p. 132).

O modelo social democrático de educação que, segundo McLaren (2000), é o modelo dominante na Europa e América, tem ampliado o espaço para conservadores redefinirem e remodelarem ideologicamente a educação. Escolas e universidades estão se tornando "mecanismo de ofertas planejadas para satisfazer um mercado mundial cada vez mais competitivo" (MCLAREN, 2000, p. 28). Atualmente, a preocupação do modelo social democrático é ensinar aos estudantes, nas escolas, como se "metacomunicarem" e como desenvolverem "meta-habilidades" e seguirem o caminho que os levará ao mundo tecnológico. Para McLaren (2000), pouca atenção é dada à ideia de se utilizar a metacomunicação e a meta-habilidades a serviço de uma ordem social mais justa e igualitária, na qual esse modelo seja colocado sob crítica com base moral e política. Desse modo, ele questiona:

\footnotetext{
Como pode a aprendizagem de meta-habilidades fazer diferença num país como os Estados Unidos, onde 20 grupos da grande imprensa [...] controlam mais da metade das vendas de jornais diários, onde $98 \%$ de todos os jornais representam um único jornal da cidade? (MCLAREN, 2000, p. 33).
}

Na construção do discurso de uma pedagogia mais comprometida com o multiculturalismo crítico, deve se priorizar o fim das injustiças. Para isso, as educadoras e os educadores precisam de uma narrativa que os una, sem dominar, uma metanarrativa dos direitos e das liberdades. Segundo McLaren (2000, p. 48), “a questão não é construir narrativas mestras de identidade autoral, mas reconstituir os elementos contingentes das nossas identidades". Todas essas questões, que formam o multiculturalismo crítico, devem estar no centro da formação curricular, permitindo aos educadores explorarem as maneiras pelas quais alunos e alunas são diferentes e sujeitos às inscrições ideológicas.

\section{CONSIDERAÇões FINAIS}

O mundo contemporâneo tem se deparado com o desafio de apresentar novos conceitos de cultura e convivência humana. Conceitos complexos que envolvem o pensamento 
intelectual nas escolas e nas universidades, que questionam e formulam novas interpretações sobre cultura e sua diversidade, têm enriquecido os debates entre especialistas e intelectuais no sentido de compreender essa problemática. Vimos a partir de Hall (2003, 2006) que esses conceitos envolvem uma diversidade cultural que é permanentemente o centro das inquietações das propostas multiculturalistas que abrangem novas perspectivas políticas que buscam os grupos marginalizados social e culturalmente. E essas perspectivas abarcam procedimentos de identificação mais variáveis e problemáticos em circunstâncias que experimentam uma concepção de identidade do sujeito mais transitória e contraditória decorrentes de novas relações entre esses sujeitos. Relações essas que são mais hibridas e por conseguinte se tornam uma ameaça à autoridade cultural. Homi Bhabha (2005) propõe que são essas perspectivas que nos possibilitam ver que cada um desses sujeitos traz uma herança cultural significativa e isso define a comunicação que se estabelece em todas as dimensões da vida.

O espaço escolar e suas instituições de ensino formal, em seus diversos graus, têm sido o local de semeadura do pensamento multiculturalista. No entanto, esse espaço e suas instituições são organizados segundo uma perspectiva homogeneizadora que não contempla, na sua grande totalidade, a diversidade e suas implicações. Preconceito, discriminação, raça, gênero, exclusão são temas silenciados dentro dos estereótipos de padrões culturais sustentados, ao longo dos anos, por cientistas e instituições de ensino. Assim, a sensibilização para a diversidade cultural e a contraposição a estereótipos e preconceitos relacionados a gênero, raça, classe social se constituem no ponto de partida para o pensamento multicultural no ambiente escolar. Aqui, o multiculturalismo crítico apontado por McLaren (2000) sugere que educadoras e educadores não repitam o essencialismo monocultural dos "centrismos" identificados por ele como o eurocentrismo, o anglocentrismo, o androcentrismo e etc., que recriam um modelo de educação que tem ampliado o espaço para conservadores redirecionar e remodelar ideologicamente a educação na Europa e na América.

Desse modo, todo o pensamento multiculturalista que aqui vimos se coloca como uma oportunidade de reconhecer e valorizar a importância da diversidade étnica e cultural na configuração de novos estilos de vida, experiências sociais, identidades e oportunidades educativas acessíveis a pessoas, grupos, nações etc. Assim, a multiculturalidade deve ser incorporada nas pedagogias educacionais para que diferentes falas e textos, dos mais diferentes grupos humanos, possam se fazer presentes na elaboração dos currículos e no questionamento dos sistemas de ensino. Para que essa perspectiva continue existindo dentro do campo educacional se faz necessário que haja uma ressignificação das estruturas curriculares que dão sustentação ao modelo atual de ensino e estimule novas reflexões sobre a formação de professores e professoras e garanta a existência das políticas educacionais que até aqui conquistamos.

\section{REFERÊNCIAS}

BHABHA, Homi K. O local da cultura. Belo Horizonte: Ed. UFMG, 2005.

HALL, S. A Identidade Cultural na Pós-Modernidade. Tradução de Tomaz Tadeu da Silva; Guacira Lopes Louro, 11. ed. Rio de Janeiro: DP\&A, 2006. 
HALL, S. Da Diáspora. Tradução de Adelaine La Guardiã, Ana C. Escosteguy, Cláudia Álvares, Francisco Rudiger, Sayonara Amaral. Belo Horizonte: UFMG, 2003.

MCLAREN, P. Multiculturalismo revolucionário: pedagogia do dissenso para o novo milênio. Porto Alegre: Artmed, 2000.

\section{DAdos do AUTOR}

Jose Carlos Santos Debus

Doutor em Educação pela Universidade Federal de Santa Catarina. Professor colaborador da

Unidade de Educação de Santa Catarina. Florianópolis/SC-Brasil.zecadebus@gmail.com

Submetido em: 1-8-2018

Aceito em: 13-8-2020 